Disponível em

http://www.anpad.org.br/rac

RAC, Rio de Janeiro, v. 18, n. 4, art. 1, pp. 372-396, Jul./Ago. 2014

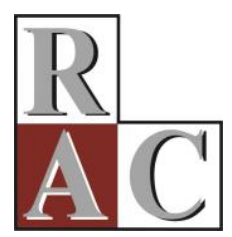

\title{
Cultura de Inovação: Conceitos e Modelos Teóricos
}

\author{
Culture of Innovation: Concepts and Theoretical Models
}

Maria de Fátima Bruno-Faria

E-mail: fatimabruno@facc.ufrj.br

Universidade Federal do Rio de Janeiro - UFRJ

Av. Pasteur, 250, Campus da Praia Vermelha, 22290-240, Rio de Janeiro, RJ, Brasil.

Marcus Vinicius de Araujo Fonseca

E-mail: vfonseca@pep.ufrj.br

Universidade Federal do Rio de Janeiro - COPPE/UFRJ

Av. Horácio Macedo 2030, Centro de Tecnologia, 21941-972, Rio de Janeiro, RJ, Brasil.

Artigo recebido em 08.08.2012. Última versão recebida em 21.05.2014. Aprovado em 23.05.2014. 


\title{
Resumo
}

O presente artigo apresenta uma abrangente revisão de literatura sobre o tema cultura de inovação, com o objetivo de caracterizar o seu significado e, principalmente, descrever diferentes modelos teóricos que buscam compreender como ele ocorre no contexto organizacional. Para enriquecer a análise, foram incluídos resultados de pesquisas que evidenciam a relação da cultura organizacional e a inovação. A pesquisa bibliográfica foi realizada em 2011, em bases disponíveis no portal da Coordenação de Aperfeiçoamento de Pessoal de Nível Superior (CAPES), na Proquest e no Directory Open Articles Journal (DOAJ), sem delimitar tempo de início. Os descritores usados foram a expressão cultura de inovação e os termos conjuntos cultura e inovação e com a inclusão somente de artigos completos. Também, foram revisados artigos relativos ao tema citados nas obras identificadas na pesquisa bibliográfica. A análise dos 40 artigos de acordo com os critérios previamente definidos permitiu revelar que se trata de um tema de interesse de pesquisadores em diferentes regiões do mundo, caracterizado por sua complexidade e pelo caráter sistêmico dos fatores que o determinam. Observou-se o predomínio de pesquisas quantitativas e forte evidência da relação de cultura organizacional e inovação, sendo necessária a realização de pesquisas nas quais os modelos teóricos propostos pelos diferentes autores sejam testados.

Palavras-chave: cultura organizacional; inovação; cultura de inovação.

\begin{abstract}
This study portrays the state of the art in scientific literature on the culture of innovation, with the objective of characterizing its meaning and especially describing different theoretical models that seek to understand how it occurs in an organizational environment. To enrich the analysis, research results show the relationship between organizational culture and innovation. The literature review was carried out in 2011 using the following databases: Coordination for the Improvement of Higher Education Personnel (CAPES), Proquest and Directory of Open Access Journals (DOAJ). The keywords used were the expression culture of innovation and the joint terms culture and innovation, only full articles were included in the research. Culture of innovation articles that were cited in the papers identified in the literature search were also considered. The analysis consisted of 40 articles, based on the predefined criteria, and showed that this is a topic of interest for researchers in different world regions. It is a complex theme determined by factors with a systemic character. There is a predominance of quantitative research and strong evidence of a relationship between organizational culture and innovation, which requires further research to test the theoretical models proposed by these different authors.
\end{abstract}

Key words: organizational culture; innovation; culture of innovation. 


\section{Introdução}

A inovação tem sido uma meta de diferentes tipos de organizações, assim, em cada realidade, aspectos devem ser observados a fim de fomentá-la ou eliminar as barreiras que podem dificultá-la. Trata-se de um construto complexo, com diferentes concepções, dimensões e contextos de aplicação que, por consequência, é compreendido sob diferentes abordagens teóricas em vários campos do conhecimento, ramos de atividade e setores industriais.

Entre os estudos sobre inovação, há aqueles que se destinam a avaliar o ambiente propício à inovação e, mais especificamente, os que, segundo Dobni (2008), buscam identificar aspectos culturais engendrados nesse processo. Tal interesse se justifica, principalmente, pelas vantagens competitivas estratégicas que as questões referentes à cultura organizacional assumem, como salientam E. Martins e Martins (2002). Uma vez que a maioria das organizações se depara com a mudança como algo inevitável, elas necessitam de uma "análise em profundidade dos valores, crenças e padrões de comportamentos que guiam o dia a dia do desempenho organizacional", acrescentam E. Martins e Martins (2002, p. 58). A capacidade de inovação também é compreendida, por Çakar e Ertürk (2010), associada à vantagem competitiva e como "uma das mais importantes dinâmicas que permite pequenas e médias empresas alcançarem um alto nível de competitividade tanto no mercado nacional quanto no internacional" (p. 327). Steele e Murray (2004) também percebem a cultura de inovação como forma de manutenção da competitividade organizacional. Os autores indicam que "a agilidade e habilidade de uma organização responder às mudanças do mercado recai no capital intelectual das pessoas" (p. 321). Isso acarreta na seleção, retenção e valorização das pessoas no trabalho (Steele \& Murray, 2004).

Dobni (2008), a partir de revisão da literatura, destaca que, recentemente, o interesse em analisar a cultura de inovação associa-se aos impactos no desempenho organizacional, sendo considerada como elemento vital para que ela ocorra, especialmente por prover vantagem competitiva. A associação com desempenho também é feita por Das (2003) ao salientar que "cultura afeta o desempenho de um negócio" e que "modos antigos são raramente os melhores modos" (p. 28).

Alguns autores ressaltam que a cultura pode se constituir como uma barreira à inovação, como observam Kaasa e Vadi (2010) quando registram o fato de a cultura tanto poder unificar comportamentos e pessoas como também se constituir em barreiras entre pessoas. Em uma abordagem sociológica, esses autores acrescentam que "cultura afeta inovação porque molda os padrões de lidar com a novidade, iniciativas individuais e ações coletivas e entendimentos e comportamentos em termos de riscos assim como de oportunidades" (p. 584).

Há pesquisadores que não tratam da cultura de inovação, mas relacionam aspectos da cultura organizacional com inovação ou, de acordo com Janiunaite e Petraite (2010), a cultura de inovação como parte da cultura organizacional.

O propósito deste estudo é analisar como a cultura de inovação tem sido conceituada, bem como os modelos teóricos adotados para a sua compreensão, presentes em trabalhos publicados em periódicos disponíveis no portal da Coordenação de Aperfeiçoamento de Pessoal de Nível Superior (CAPES), na base de dados Proquest e no Directory Open Articles Journal (DOAJ). Parte-se do princípio de que a análise dos conceitos e modelos teóricos favorece a produção de conhecimentos que contribuem para o avanço dos estudos sobre o tema, bem como para a gestão da inovação no contexto organizacional.

Este artigo foi estruturado de modo a, após introduzir o assunto, apresentar a metodologia adotada na pesquisa bibliográfica; caracterizar os artigos selecionados e, em seguida, mapear os conceitos e modelos teóricos oriundos de pesquisas científicas sobre o tema. Por fim, são sintetizados os principais achados a partir do levantamento realizado e apontadas sugestões de estudos futuros decorrentes das lacunas evidenciadas na referida análise. 


\section{Metodologia da Pesquisa Bibliográfica}

Com o propósito de evidenciar como a cultura de inovação tem sido conceituada, bem como os modelos teóricos adotados para a sua compreensão, foi realizada, em 2011 (ocasião da elaboração deste artigo e posterior submissão em 2012), pesquisa nas principais bases de dados disponíveis no país por intermédio do portal da CAPES (Emerald, JSTOR, Wiley, SAGE, ScienceDirect, Scielo, Cambridge Journals Online), na Proquest, assim como no Directory Open Articles Journal (DOAJ). Incluiu-se como área do conhecimento a multidisciplinar, o que evidenciou produção sobre o tema no campo da Administração (especialmente Business), Economia, Engenharia de Produção, Psicologia, Comportamento Organizacional, Sociologia e Antropologia, tendo como opção de busca qualquer ano e como limite o ano de tal levantamento (2011). Na realidade, buscou-se não se delimitar início da pesquisa para que se tivesse uma ideia de quando o assunto passou a ser objeto de atenção na literatura científica.

Buscou-se, ainda, revisar tanto artigos que se valem da análise da cultura de inovação como objeto central ou como um dos focos do estudo quanto aqueles que realizam pesquisas com o propósito de verificar a relação entre cultura organizacional ou cultura corporativa, como Shieh e Wang (2010) denominam, e inovação. Adotaram-se as palavras-chave cultura de inovação e os termos conjuntos cultura e inovação como operadores booleanos AND e e. Foram excluídos artigos que tratassem de cultura nacional ou regional (como Van Reine \& Dankbaar, 2011), pois se privilegiava a análise do contexto organizacional que o conceito de cultura de inovação engendra. Dada a ampla variedade de estudos identificados e o objetivo desta pesquisa, optou-se por tratar, em outra publicação, dos instrumentos de medida empregados para avaliar cultura de inovação ou cultura organizacional relacionada à inovação.

$\mathrm{Na}$ análise do conteúdo de cada artigo, buscou-se identificar os seguintes elementos:

1. Caracterização dos artigos selecionados: quantidade de artigos, ano de publicação, o foco do estudo (se tratavam de cultura de inovação ou da associação entre cultura organizacional e inovação); periódicos em que foram publicados; classificação dos artigos de acordo com o método (ensaios; pesquisas qualitativa, quantitativa ou mista).

2. Conceitos de cultura de inovação.

3. O modelo teórico proposto ou adotado pelo autor com a descrição das respectivas variáveis que o integram. Cabe esclarecer que todos os modelos teóricos incluídos nos artigos analisados foram descritos neste estudo.

4. Conclusões apontadas pelo autor.

Entre as limitações da pesquisa bibliográfica, salienta-se o fato de as bases de dados consultadas, muitas vezes, terem iniciado a disponibilização de artigos em datas mais recentes, assim, podendo existir produções anteriores não encontradas neste levantamento. Outro fato é que alguns artigos não foram disponibilizados a partir de acesso livre nas bases consultadas, não sendo, por tal motivo, objeto de análise. Outrossim, acredita-se que a ampla diversidade de propostas de análise da cultura de inovação retratada neste artigo possa contribuir para o surgimento de novos estudos sobre o tema.

\section{Resultados do Levantamento: Caracterização dos Artigos Selecionados}

Foram selecionados 40 artigos que tratavam de cultura de inovação ou da relação da cultura organizacional com a inovação, sendo que o mais antigo era de 1997. Nesse total, incluem-se obras identificadas nas referências dos artigos analisados, a exemplo do artigo de Dombrowski et al. (2007) e outros. 
Na Figura 1, pode ser observado o quão recente é a produção de artigos sobre o tema.

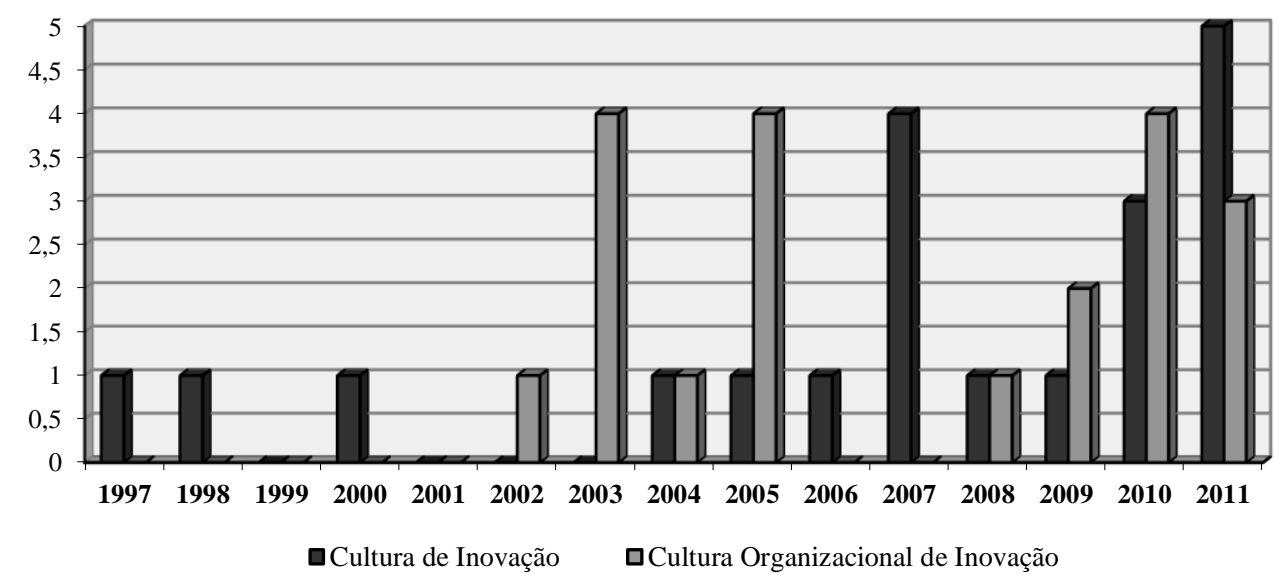

Figura 1. Produção Científica sobre Cultura de Inovação e Cultura Organizacional e Inovação (19972011).

É nítida a crescente atenção dada ao assunto nos últimos cinco anos, sendo Zien e Buckler (1997) e Ahmed (1998) os autores das obras mais antigas identificadas quanto ao tema nas bases pesquisadas. O número de artigos sobre cultura de inovação é semelhante aos dedicados à análise da relação entre cultura organizacional e inovação. Dos 40 artigos, nove são ensaios teóricos; seis, pesquisas qualitativas; 21 , pesquisas quantitativas; e quatro, pesquisas mistas. Cabe ressaltar que os autores revisados neste estudo pertenciam/pertencem a universidades situadas em diferentes regiões do mundo, tais como: África do Sul, Arábia, Austrália, Bélgica, Brasil, Canadá, Croácia, Eslovênia, Espanha, Estônia, EUA, Japão, Índia, Líbia, Lituânia, Malásia, Noruega, Reino Unido, Suíça, Tailândia, Taiwan, Turquia e Vietnã, revelando que o tema é foco de atenção em diferentes culturas e países.

Dos 40 artigos analisados, quatro foram extraídos do European Journal of Innovation Management, dois do Knowledge and Process Management e, em cada um dos periódicos descritos na Tabela 1 foi identificado um artigo sobre o tema com os critérios previamente definidos. Observa-se que apenas um artigo não foi publicado em periódico científico, mas apresentado em evento científico na forma de artigo completo ( $31^{\text {st }}$ Institute for Small Business \& Entrepreneurship Conference). Dos periódicos analisados nas bases consultadas, três são nacionais (Revista Eletrônica de Ciência Administrativa [RECADM]; Revista de Gestão e Projetos [GeP]; e Revista de Gestão USP [REGE]).

Tabela 1

\section{Periódicos com Artigos Incluídos na Análise}

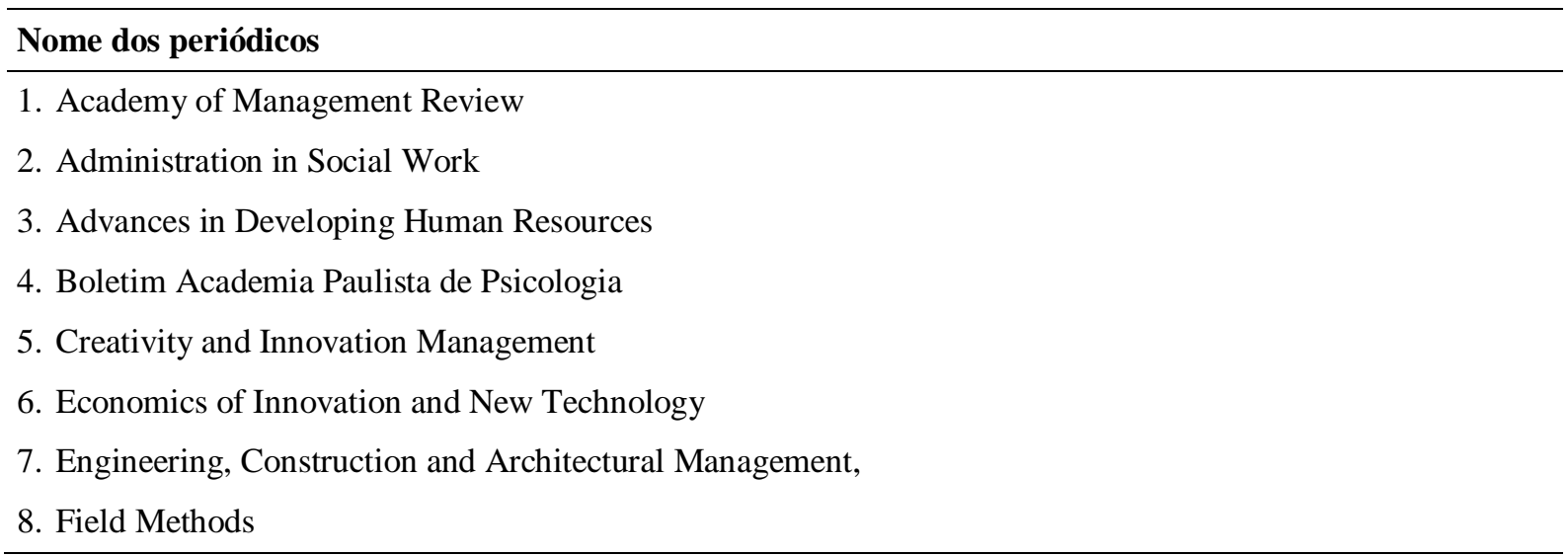




\section{Tabela 1 (continuação)}

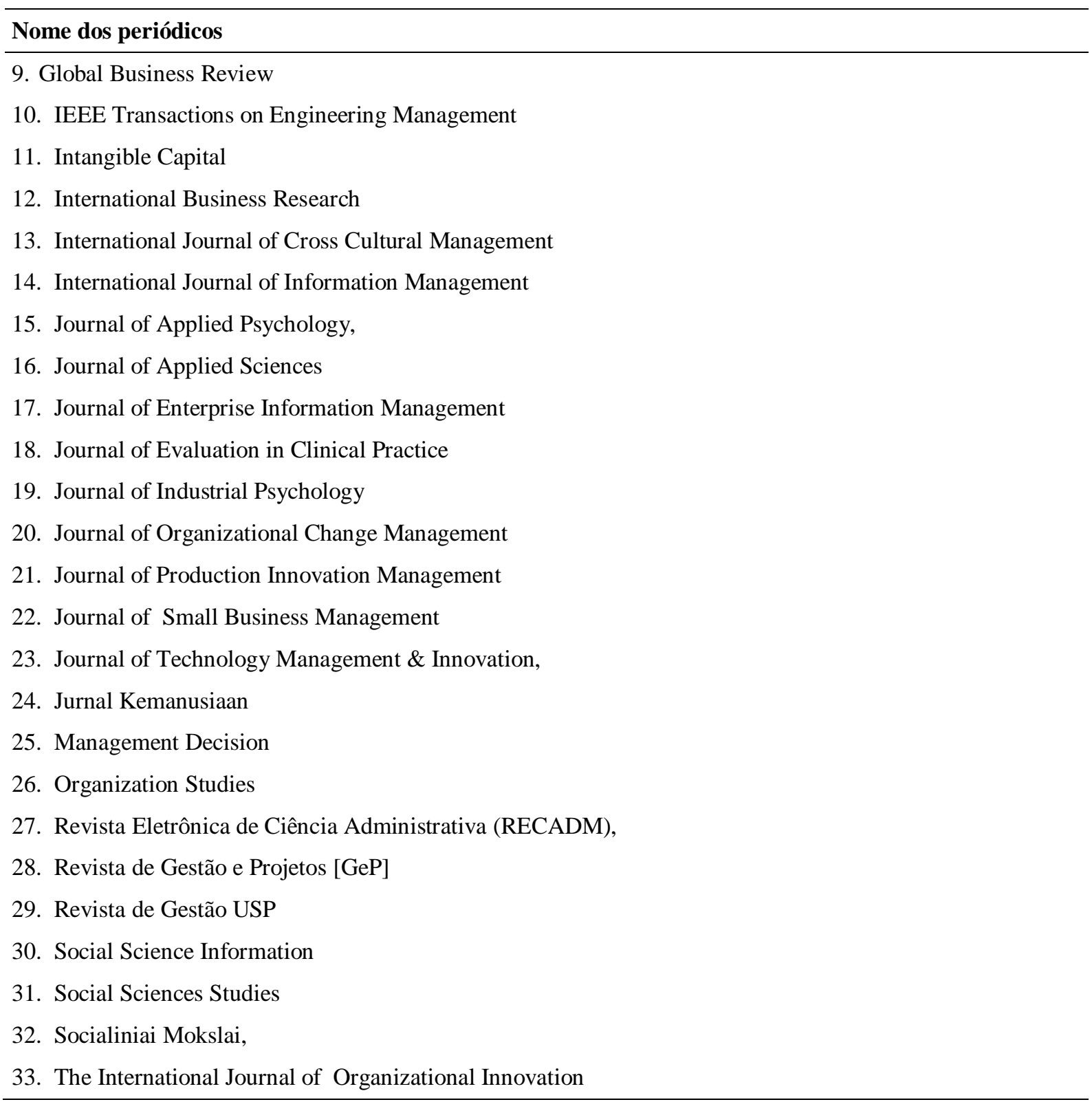

\section{Cultura de inovação: diferentes concepções}

Dobni (2008) destaca que "em um ambiente organizacional, inovação é frequentemente expressa através de comportamentos ou atividades que são em última análise ligados a uma ação ou resultado tangíveis" (p. 540). Assim concebida, a cultura de inovação, segundo o autor,

tem sido definida como um contexto multidimensional que inclui a intenção de ser inovativo, a infra-estrutura que dá suporte à inovação, comportamento de nível operacional necessários a influenciar o mercado e a orientação de valor e o ambiente para implementar a inovação (Dobni, 2008, p. 540).

Percebe-se, nessa definição, a concepção abrangente do contexto, incluindo aspectos estruturais e comportamentais, além de fatores internos e externos à organização.

Cultura de inovação, para Zien e Buckler (1997), compreende "líderes de todos os níveis das empresas altamente bem sucedidas e maduras contando e recontando estórias de experiências e 
explorações inovativas" (p. 275). Adotam uma perspectiva antropológica cultural na busca de compreender como esses tipos de empresas mantêm "o espírito inovativo vibrante e robusto empregando princípios de inovação" (Zien \& Buckler, 1997, p. 276).

Apekey, McSorley, Tilling e Siriwardena (2011) seguem uma visão antropológica de cultura que compreende valores, ideias, conceitos e regras de comportamento compartilhados por um grupo social a fim de possibilitar seu funcionamento e perpetuá-lo. Denominam-na "cultura de inovação dentro das práticas" ou "cultura de melhoria dentro das práticas" (p. 312) e sua análise revelou a existência de sete dimensões: risco, recursos, informação, metas, ferramentas, recompensas e relacionamentos.

De acordo com Janiunaite e Petraite (2010, p. 14), por sua vez, cultura de inovação relaciona-se com gestão do conhecimento e é um "determinante da inovação sustentável", bem como do "desempenho efetivo de uma organização".

Serra, Fiates e Alpersted (2007) destacam a importância de uma cultura inovadora para um ambiente favorável à inovação. Salientam que

uma postura inovadora nem sempre é fácil, pois depende de um ambiente favorável, de pessoas criativas e sem medo de errar, de recursos para pesquisas e uma interação muito próxima com o mercado e seus atores, de modo a perceber as oportunidades existentes (Serra, Fiates, \& Alpersted, 2007, p. 182).

Mambrini, Dattein, Medina, Cintho e Maccari (2011) investigaram práticas gerenciais que promovem uma cultura inovadora e sua contribuição para a capacidade de inovação de pequenas e médias empresas brasileiras. Destacam que a inovação se vale de ideias oriundas tanto de fontes internas quanto externas para ganhar competitividade. E empregam o modelo de cinco componentes que promovem inovação nas organizações, proposto por Cunha (2005 como citado por Mambrini, Dattein, Medina, Cintho, \& Maccari, 2011) que contempla: estratégia e posicionamento de mercado; estrutura e ambiente organizacional interno; gestão de tecnologia; gestão de pessoas; e gestão de parcerias.

Das concepções de cultura de inovação revisadas neste estudo, dá-se ênfase às características do ambiente organizacional (Dobni, 2008) e dos líderes (Zien \& Buckler, 1997); no capital intelectual (Steele \& Murray, 2004); na gestão do conhecimento (Janiunaite \& Petraite, 2010); nas normas culturais (Apekey, McSorley, Tilling, \& Siriwardena, 2011; E. C. Martins \& Terblanche, 2003); no ambiente, pessoas, recursos e interação com o mercado (Mambrini et al., 2011; Serra et al., 2007).

\section{Relação entre cultura organizacional e inovação}

Cultura organizacional é um tema, muitas vezes, tratado de forma indistinta de clima organizacional; da mesma maneira criatividade o é em relação à inovação, como salienta McLean (2005). A autora analisa as principais contribuições na produção científica sobre os temas e, assim como Amabile (1996), afirma que criatividade se refere ao nível individual, enquanto que inovação se relaciona aos níveis de grupo e organizacional. Entretanto, cabe salientar as pesquisas de West e Anderson (1996), entre outros, que apontam as especificidades do processo criativo em grupos. A inovação é entendida, segundo Amabile (1996) e Van de Ven e Angle (2000), como o processo de implementação dessas ideias.

Segundo McLean (2005, p. 241), "a cultura cria os parâmetros para qual comportamento é desejável e será encorajado e qual comportamento é inaceitável e será censurado". Em relação aos aspectos da cultura organizacional que favorecem a criatividade e inovação, McLean (2005) destaca os seguintes: "encorajamento organizacional; encorajamento do supervisor; encorajamento do grupo de trabalho; liberdade/autonomia e recursos" (p. 241). No tocante aos fatores da cultura que impedem a inovação, destaca-se o controle.

Ahmed (1998), também, ressalta a importância de analisar clima e cultura organizacional para inovação. $\mathrm{O}$ clima pode ser observado nas práticas e políticas organizacionais, enquanto que as crenças 
e valores que representam a cultura não podem ser assim notados por serem mais profundos. A cultura relaciona-se com as interpretações feitas pelos empregados sobre as experiências vividas na organização "porque as coisas são do jeito que são e o modo e o porquê das prioridades organizacionais" (p. 32).

Em alguns casos, autores empregam a expressão cultura de inovação, mas aplicam instrumentos de medida de cultura organizacional. Na pesquisa de Twati e Gammack (2006), por exemplo, cujo título menciona cultura de inovação, os autores utilizam um modelo de cultura organizacional para identificar os principais aspectos que impediam organizações libanesas a adotarem sistemas de informação.

Há, porém, aqueles como E. Martins e Martins (2002), que buscaram “identificar, operacionalizar, medir e descrever os determinantes da cultura organizacional que podem influenciar a criatividade $\mathrm{e}$ inovação" (p. 58). Os autores centram sua atenção nos aspectos da cultura organizacional que fomentam a criatividade e inovação e observam que

no meio da mudança, organizações e líderes estão tentando criar uma estrutura institucional na qual criatividade e inovação são aceitas como normas básicas culturais. Tem se tornado claro que 'regras não escritas do jogo' (as normas de comportamento) e valores compartilhados influenciam a moral, o desempenho e a aplicação de criatividade e inovação sob diferentes formas (E. Martins \& Martins, 2002, p. 58).

No tocante aos recursos, Le Bas e Lauzikas (2010) observam que uma arquitetura que dê suporte à estratégia de inovação requer recursos financeiros, recursos humanos e cultura de inovação. Já a cultura de inovação abrange a arquitetura organizacional e seus principais responsáveis; ferramentas gerenciais na prática; seleção e implementação de novas ideias, o papel do líder, criatividade dos empregados, entre outros aspectos.

Duygulu, Kök e Özdemir (2008) analisaram o impacto do ambiente operacional, cultura organizacional e estrutura organizacional (variáveis independentes) sobre a capacidade de inovação (variável dependente). A análise foi realizada junto a 3.034 pequenas e médias empresas da Turquia. Uma das hipóteses do estudo era a de que a cultura organizacional apresentava uma relação negativa com a capacidade de inovação. Entretanto os resultados evidenciaram uma relação positiva da cultura organizacional com a capacidade de inovação, porém com baixo nível de explicação.

Jaskyte e Dressler (2004), em uma perspectiva antropológica, destacam a importância do nível de análise no estudo da cultura. Trazem uma discussão a respeito da pertinência de estudar cultura em um nível de análise individual. A partir de conceitos oriundos da epidemiologia, propõem dois tipos de variáveis: (a) uma variável individual integral, referente às propriedades dos seres humanos; e, (b) uma variável integral agregada que descreve propriedades de grupos de seres humanos. O nível de análise que propõem como variável agregada integral "é a variável na qual o referente é algum grupo de indivíduos, mas não pode ser reduzido a um sumário de propriedades de indivíduos que compõem o grupo" (p. 268). Jaskyte e Dressler (2004) introduzem ainda a "ideia de consenso subjacente à cultura que permite que "coisas' culturais existam para todos" (p. 269). Uma vez que cultura é concebida como o conhecimento aprendido e compartilhado, há necessidade de consenso para que esse compartilhamento ocorra levando a uma compreensão semelhante do domínio. Assim, "a força da associação entre os entendimentos individuais de um domínio é evidência tanto da força geral do consenso em um domínio particular como do grau no qual cada indivíduo compartilha no consenso" (Jaskyte \& Dressler, 2004, p. 270).

Esses autores consideram a inovação, o conteúdo da cultura e o grau em que a cultura é compartilhada como atributos organizacionais. Aplicam, nesse sentido, a ideia da necessidade da análise de consenso cultural para estimar as dimensões da cultura para inovação no contexto organizacional. A definição de cultura organizacional por eles adotada é vista como "um conjunto de valores compartilhados que auxiliam os membros da organização a compreender o funcionamento organizacional e assim guiar o pensamento e comportamento" (Jaskyte \& Dressler, 2004, p. 274).

Entre os poucos estudos encontrados no âmbito nacional, destaca-se o trabalho desenvolvido por Machado e Vasconcellos (2007), que associam inovação organizacional à existência de uma cultura 
propícia a sua emergência. Esse estudo concentra-se no mapeamento de ambientes organizacionais que revelam as características dessa cultura. Adotam, para tanto, a concepção de cultura proposta por Geertz (1989 como citado por Machado \& Vasconcellos, 2007), que engloba compartilhamento de símbolos e significados entre atores dentro de um determinado sistema social. Os elementos mapeados que integram a cultura são: valores, crenças e pressupostos, ritos, rituais e cerimônias, histórias e mitos, tabus, heróis, normas, comunicação, artefato e símbolo. Os valores foram os elementos mais típicos das organizações inovadoras, seguidos de crenças e pressupostos. Os artefatos e símbolos, por sua vez, apresentaram baixos percentuais na pesquisa.

Godoy e Peçanha (2009), em pesquisa no Brasil, buscaram investigar a relação de cultura organizacional e processos de inovação organizacional a partir de uma abordagem psicossociológica. Evidenciaram os seguintes aspectos da cultura organizacional relacionados à inovação: gestão estruturada dos processos de inovação; trabalho em equipe; suporte das lideranças; comunicação aberta; tolerância à ambiguidade; estímulo ao desenvolvimento de confiança; reconhecimento por todos da importância estratégica da inovação; e abertura à exposição de ideias.

A comunicação é um aspecto presente em muitos estudos sobre facilitadores da inovação. Johannessen e Olsen (2011), por exemplo, consideram essencial que se transformem processos de comunicação em capacidades de comunicação. Para isso, deve envolver criação de valor e ser orientada para desenvolvimento, transferência e integração do conhecimento. A cultura de inovação necessita de mecanismos de coordenação e interação que abranjam trocas de informações e conhecimentos que contribuam para o desenvolvimento do conhecimento - que é a base para a inovação. As capacidades de comunicação constituem um sistema que preserva a criação de valor e combina comunicação econômica/técnica; gestão da comunicação; e comunicação social e cultural.

Segundo Das (2003), quando a comunicação associa-se ao compartilhamento de uma cultura, os empregados tendem a ser mais unidos em suas ações, o que interfere em seu desempenho. $\mathrm{O}$ autor compara uma cultura forte com a identidade de uma organização, que, por ser única, possibilita que clientes, fornecedores, empregados e investidores percebam seu caráter distintivo em relação a outras empresas.

Conquanto não seja possível reduzir os diferentes achados em uma frase, destaca-se que a relação entre cultura organizacional e inovação pode ser entendida como: um ambiente organizacional em que haja espaços para a criatividade das pessoas e que o sistema de comunicação permita o compartilhamento de ideias, informações, experiências e valores que tenham a inovação como foco principal.

\section{Modelos teóricos buscam explicar a cultura de inovação ou a relação de cultura organizacional e inovação}

A partir de revisão da literatura sobre cultura de inovação, Dobni (2008) propõe um modelo de cultura de inovação geradora de desempenho organizacional, conforme Figura 2, a seguir. 


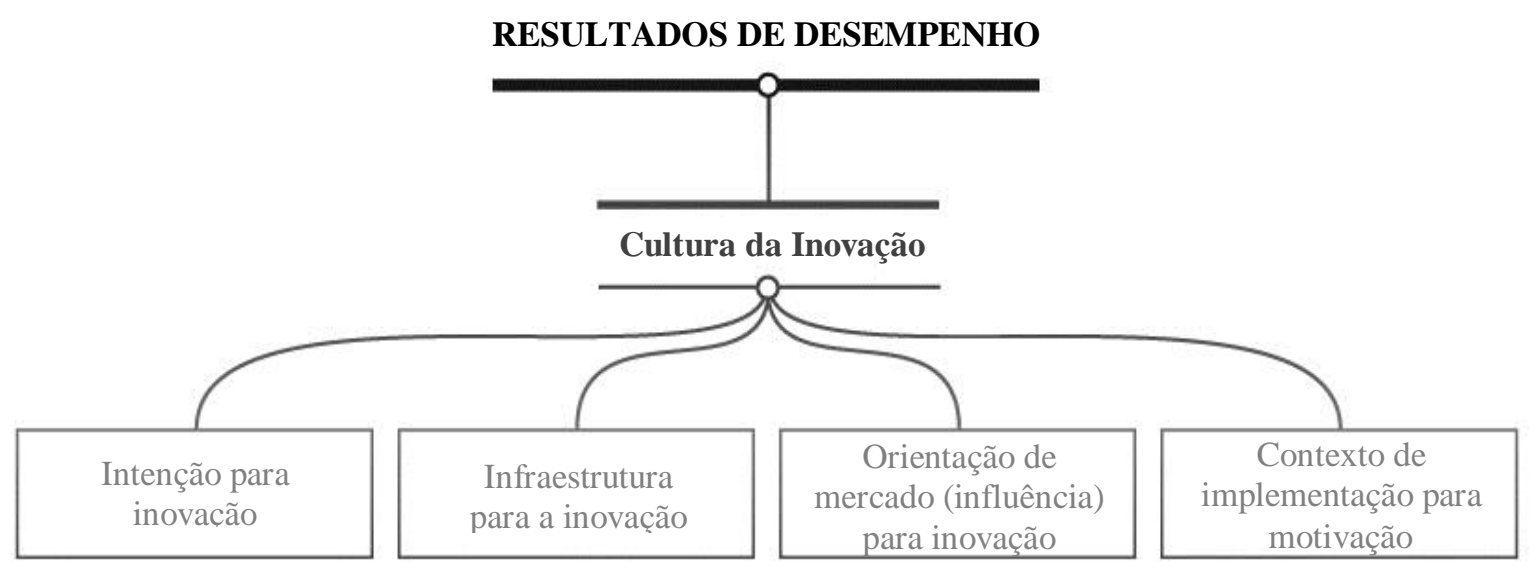

Figura 2. Modelo de Inovação.

Fonte: Adaptado de Dobni, C. B. (2008). Measuring innovation culture in organizations: the development of a generalized innovation culture construct using exploratory factor analysis (p. 541). European Journal of Innovation Management, 11(4), 539-559. doi: 10.1108/14601060810911156

O modelo teórico proposto por Dobni (2008) inclui

a intenção de ser inovativo; a infra-estrutura para dar suporte à inovação; o conhecimento e orientação aos empregados para dar suporte aos pensamentos e ações necessários à inovação e um ambiente ou contexto para dar suporte à implementação - o qual invariavelmente tem risco inerente e recompensas em troca (p. 552).

Zien e Buckler (1997), objetivando a construção de um modelo de como as organizações criam e sustentam uma cultura de inovação, analisaram 12 diferentes corporações. Observaram que naquelas caracterizadas por serem inovativas, os líderes "demonstravam em todas as decisões, ação, e comunicação de que inovação impulsiona a rentabilidade" (p. 274). Os líderes, também, eram responsáveis pelo estabelecimento de metas desafiantes. As organizações, por sua vez, devem estabelecer métricas e objetivos vinculados às metas de negócios e medidas de desempenho de grupos e individuais.

Bravo-Ibarra e Herrera (2009) definiram cultura como "o conjunto de valores, normas e comportamentos dos membros de uma organização" (p. 308) e propuseram um modelo conceitual baseado na perspectiva de capacidades dinâmicas, como mostra a Figura 3.

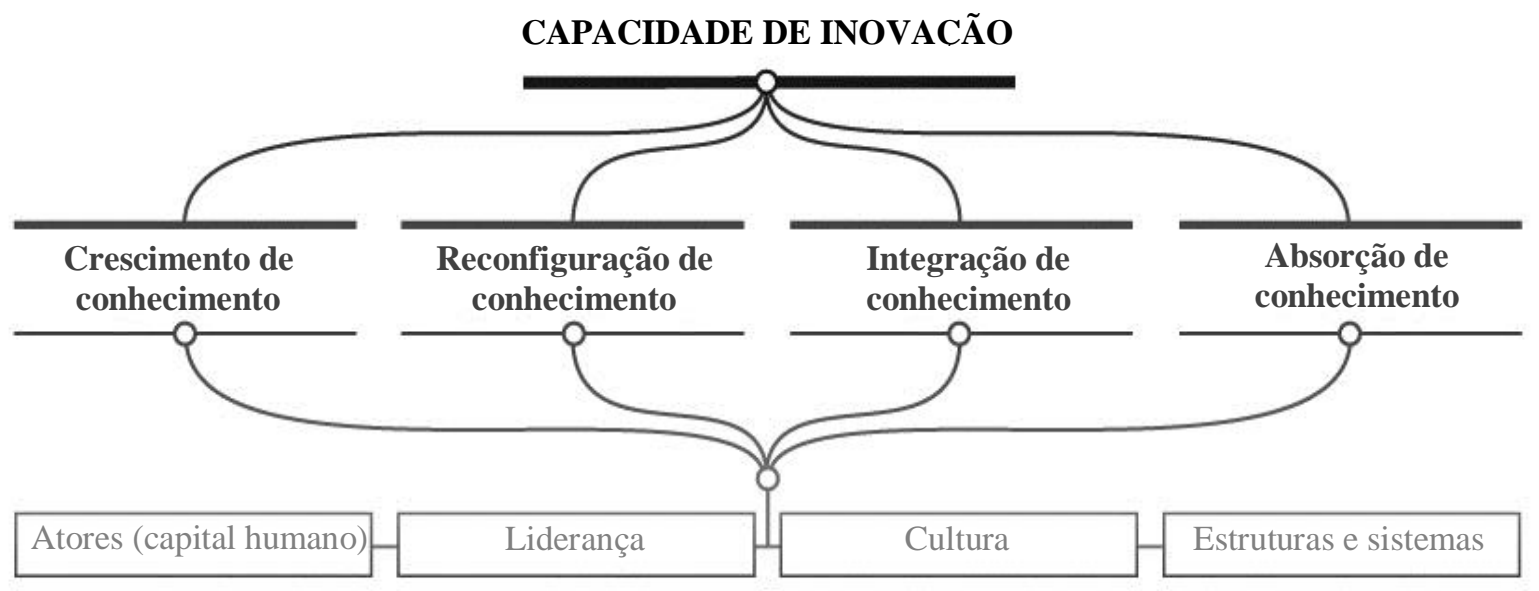

Figura 3. Modelo Conceitual da Capacidade de Inovação.

Fonte: Adaptado de Bravo-Ibarra, E. R., \& Herrera, L. (2009). Capacidad de innovación y configuración de recursos organizativos (p. 314). Intagible Capital, 5(3), 301-320. doi: 10.3926/ic.2009 
Bravo-Ibarra e Herrera (2009), a partir de estudos de casos, identificaram um conjunto de 33 boas práticas geradoras da capacidade de inovação associadas a cada um dos quatro recursos ilustrados na Figura 3, extraídos da revisão de literatura. Entre elas, sete práticas foram associadas à cultura da organização. São as seguintes:

liberdade de exploração de temas relacionados com competências centrais; atitude aberta para a comunidade científica; predisposição à criatividade; ausência de identificação departamental; fomento do diálogo e a interação; comunicação frequente, informal, direta e aberta e comunidades de intercâmbio de conhecimento on-line com clientes e empregados (Bravo-Ibarra \& Herrera, 2009, p. 315).

Os resultados do estudo evidenciaram que a liderança e suas práticas correspondentes tiveram uma contribuição fundamental para a construção da capacidade de inovação da organização. BravoIbarra e Herrera (2009) ressaltaram que esses três processos de conhecimento têm como suporte os seguintes tipos de recursos: os atores/capital humano, a liderança, as estruturas e sistemas e a cultura organizativa.

E. Martins e Martins (2002) adotaram um modelo sistêmico a fim de identificar a "interação entre subsistemas organizacionais (objetivos, estrutura, gestão, tecnologia e psicossociológico)" (p. 59) que compreende diferentes níveis entre indivíduos e grupos e outras organizações e o ambiente externo para identificar os "determinantes que influenciam criatividade e inovação em uma perspectiva cultural, e comparar os achados com o modelo baseado na literatura estudada" (p. 59). Na Tabela 2, encontra-se a representação do modelo composto por sete fatores que buscam explicar a influência da cultura organizacional na criatividade e inovação em uma organização voltada para serviços.

Tabela 2

Fatores que Afetam a Criatividade e Inovação Organizacional

\section{DETERMINANTES DA SIGNIFICADO \\ CULTURA ORGANIZACIONAL}

\begin{tabular}{ll}
\hline Estratégia & $\begin{array}{l}\text { Uma estratégia que conduz à criatividade e inovação em uma } \\
\text { organização é descrita na visão e missão como uma orientação de } \\
\text { marketing focada no cliente. Inclui também pesquisa ativa sobre } \\
\text { as necessidades de clientes existentes e potenciais com uma visão } \\
\text { de promover a criatividade e a inovação. }\end{array}$ \\
$\begin{array}{ll}\text { Os empregados devem compreender que a visão e a missão } \\
\text { Intencionalidade }\end{array}$ & $\begin{array}{l}\text { influenciam na implementação, uma vez que elas devem fazer } \\
\text { menção à criatividade e à inovação. Os objetivos devem ser } \\
\text { diretos, quantitativos e relacionados a tempo para produtos e } \\
\text { serviços criativos. }\end{array}$ \\
& $\begin{array}{l}\text { Gerentes e empregados devem manter uma comunicação aberta } \\
\text { uns com os outros. As pessoas precisam se sentir }\end{array}$ \\
Relacionamento de confiança & $\begin{array}{l}\text { emocionalmente seguras. Deve haver apoio para mudança através } \\
\text { de comportamentos que encorajam a inovação. Deve haver } \\
\text { flexibilidade no modo de fazer as coisas no trabalho. }\end{array}$ \\
Comportamento que encoraja inovação & $\begin{array}{l}\text { Criação de valores que apoiam o correr riscos, o encorajamento } \\
\text { de ideias, da iniciativa de se buscar novas soluções para os } \\
\text { problemas e da tomada de decisão. }\end{array}$ \\
\hline
\end{tabular}


Tabela 2 (continuação)

\begin{tabular}{l}
\hline DETERMINANTES DA \\
CULTURA ORGANIZACIONAL
\end{tabular}

\begin{tabular}{ll}
\hline Ambiente de trabalho & $\begin{array}{l}\text { A realização de metas e objetivos pessoais em buscar metas e } \\
\text { objetivos organizacionais. O saber lidar com conflitos de forma } \\
\text { construtiva, a presença de equipes cooperativas, liberdade para } \\
\text { gerar ideias, a participação na tomada de decisão e a ação de } \\
\text { desenvolver melhores métodos de trabalho. }\end{array}$ \\
\hline Orientação para o cliente & $\begin{array}{l}\text { Compreensão das necessidades dos clientes internos e externos, } \\
\text { aprimoramento e flexibilidade do serviço ao cliente. A reação às } \\
\text { necessidades do cliente deve ser flexível. O foco é na orientação } \\
\text { ao cliente no nível operacional. } \\
\text { Comunicação aberta entre gerentes e empregados e entre } \\
\text { empregados, disponibilidade de equipamentos e recursos } \\
\text { dependente do suporte do gerente. Tolerância dos gerentes ao } \\
\text { erro dos empregados. O apoio dos gerentes na adaptação de } \\
\text { regras e regulamentos. }\end{array}$ \\
\hline
\end{tabular}

Nota. Fonte: a partir de Martins, E., \& Martins, N. (2002). An organizational culture model to promote creativity and innovation. Journal of Industrial Psychology, 28(4), 58-65.

O modelo proposto por E. Martins e Martins (2002) mostra-se abrangente e com elementos apontados em diferentes estudos cujo foco é na promoção da inovação. Entretanto cabe destacar que, ao explicarem os fatores que integram o modelo, há uma superposição de aspectos, tais como os evidenciados nos fatores: comportamento que encoraja inovação, ambiente de trabalho e o suporte do gerente. Para uma análise mais criteriosa, seria necessário o acesso às definições operacionais dos fatores, não disponibilizado pelos autores. A partir do modelo proposto por Martins (2000 como citado por E. C. Martins \& Terblanche, 2003), E. C. Martins e Terblanche (2003) evidenciam a falta de concordância entre os teóricos em relação aos fatores da cultura que apoiam a inovação. Dessa forma, propõem um modelo interativo integrado de determinantes da cultura que influenciam a criatividade e a inovação, a partir dos achados da literatura. Além desses aspectos contemplados na Figura 4, ações de gestão de pessoas, tais como recrutamento, seleção e nomeações, são consideradas, por esses autores, como mecanismos importantes para promover a cultura e, de forma mais específica, a criatividade e a inovação. 


\section{DIMENSÕES MEDIDAS PARA DESCREVER CULTURA ORGANIZACIONAL}

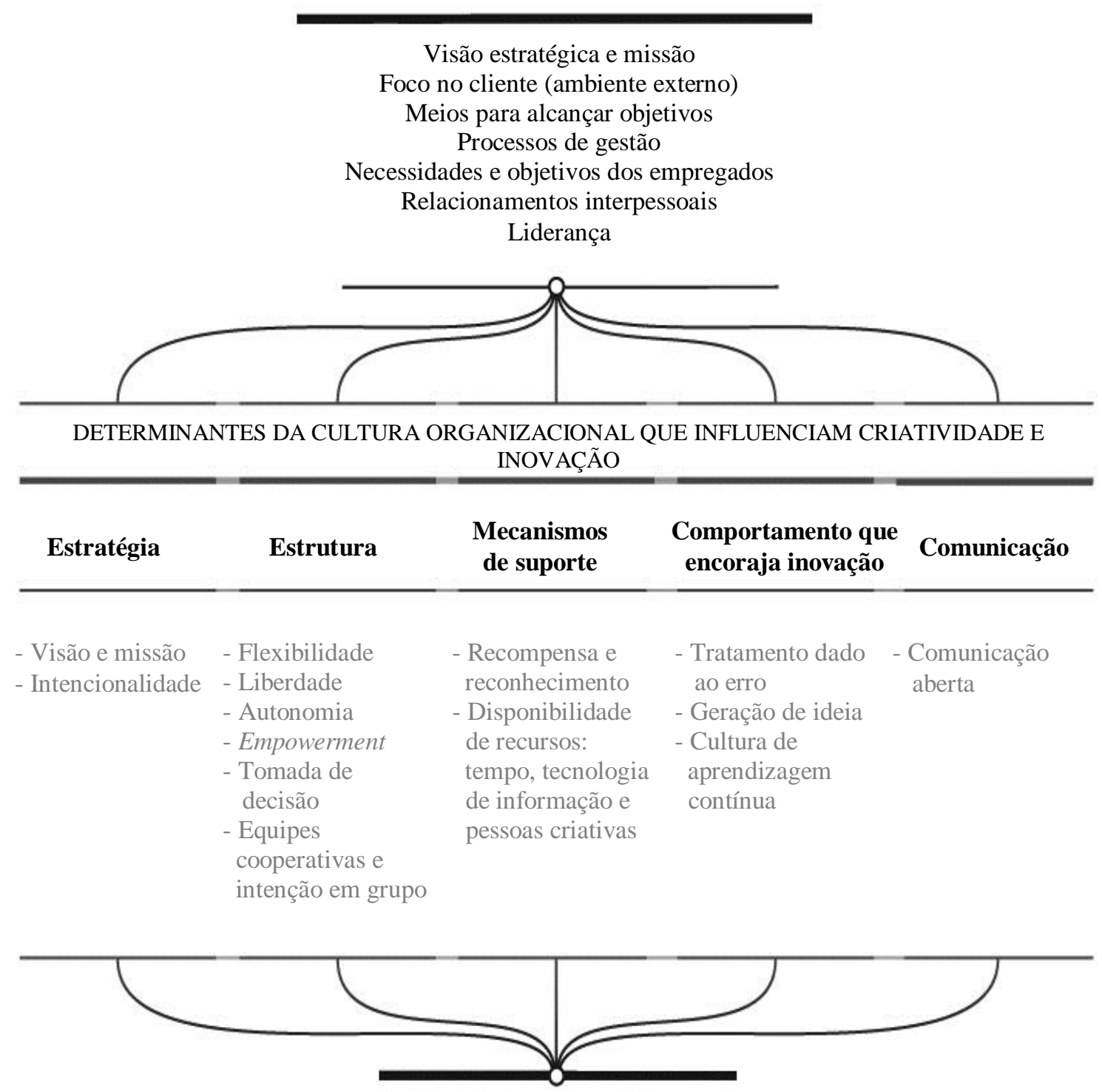

CRIATIVIDADE E INOVAÇÃO

Figura 4. Influência da Cultura Organizacional na Criatividade e Inovação.

Fonte: Adaptado de Martins, E. C., \& Terblanche, F. (2003). Building organizational culture that stimulates creativity and innovation (p. 70). European Journal of Innovation Management, 6(1), 64-74. doi: 10.1108/14601060310456337

Outra crítica a ser feita no modelo de E. Martins e Martins (2002) e E. C. Martins e Terblanche (2003) é a consideração de que os fenômenos da criatividade e inovação são semelhantes, quando a literatura científica tem apontado inter-relações dos construtos, assim como a necessidade de diferenciálos para que se possa melhor compreendê-los e gerenciá-los (Amabile, 1996).

Çakar e Ertürk (2010), a partir da ideia de que "cultura organizacional é baseada nos valores compartilhados relacionados aos empregados que são influenciados pela cultura no nível societal" (p. 328), "examinaram a relação entre cultura organizacional, percepções de empowerment e capacidade de inovação em termos do tamanho da firma" (p. 333). Na Figura 5, encontra-se o modelo proposto pelos autores. 


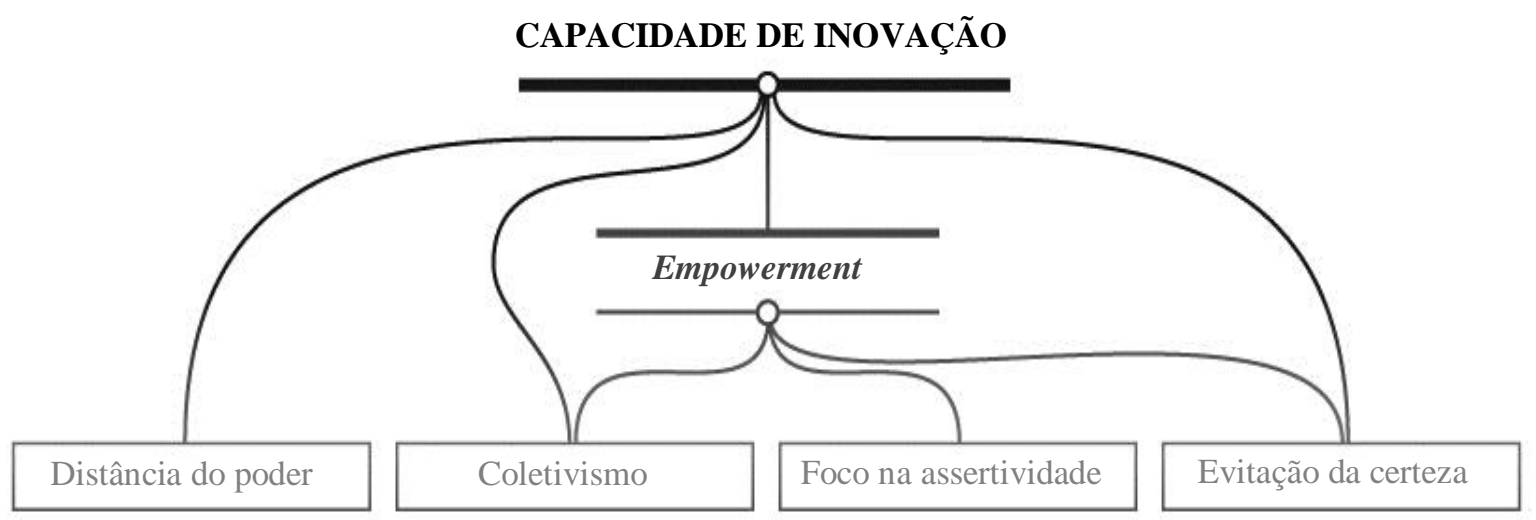

Figura 5. Modelo Revisado para Amostras de Pequenas e Médias Empresas.

Fonte: Adaptado de Çakar, N. D., \& Ertürk, A. (2010). Comparing innovation capability of small and medium-sized enterprises: examining the effects of organizational culture and empowerment (p. 342). Journal of Small Business Management, 48(3), 325-359. doi: 10.1111/j.1540-627X.2010.00297.x

Para conceituar cultura organizacional, Çakar e Ertürk (2010) valem-se tanto dos conceitos de Schein como daqueles de Hofstede. Em relação à Schein, utilizam a ideia de cultura como "valores compartilhados e pressupostos que guiam o comportamento em uma organização" (p. 327). E apropriam-se das quatro dimensões propostas por Hofstede para descrever cultura, a saber: distância do poder, evitar incertezas, individualismo/coletivismo e masculinidade/feminilidade. Kaasa e Vadi (2010) também empregaram tal modelo de cultura para estudar o processo de iniciação de uma inovação. Segundo eles, esse processo é derivado da criatividade individual que, por sua vez, é influenciada tanto pela cultura organizacional como pela cultura social mais ampla. Para melhor compreensão dos resultados do estudo que realizaram, optou-se por descrever, na Tabela 3, o significado dessas dimensões.

Tabela 3

Dimensões e Respectivos Significados da Cultura Organizacional que se Relacionam com Capacidade de Inovação

\begin{tabular}{ll}
\hline DIMENSÕES & SIGNIFICADOS \\
\hline Distância do poder & $\begin{array}{l}\text { Centra na extensão pela qual membros da organização se sentem confortáveis } \\
\text { em interações através dos níveis hierárquicos. }\end{array}$
\end{tabular}

Evitar incertezas

Refere-se ao grau ao qual os membros da organização querem evitar ambiguidades e incertezas a favor de objetivos claros e diretrizes operacionais.

Individualismo/Coletivismo Relaciona-se com a extensão na qual pessoas preferem ser tratadas como indivíduos únicos ao invés de uma parte de um grupo. Nas culturas coletivistas, pessoas sentem conforto e energia no ambiente do grupo, enquanto que nas culturas individualistas, as pessoas querem ser capazes de se destacar como indivíduos e não serem detidas pelo grupo. Coletivismo está em uma das extremidades de um continuum e o individualismo na outra.

Masculinidade/Feminilidade Concentra-se no grau ao qual as pessoas sentem que devem se focar em (Obs. Çakar e Ertrük, 2010, resultados e serem insensíveis a emoções versus sentimento de que devem ser optam pelo termo foco na menos focadas em resultados e mais sensíveis a emoções. assertividade)

Nota. Fonte: A partir de Çakar, N. D., \& Ertürk, A. (2010). Comparing innovation capability of small and medium-sized enterprises: examining the effects of organizational culture and empowerment (pp. 327-330). Journal of Small Business Management, 48(3), 325-359. doi: 10.1111/j.1540-627X.2010.00297.x e de Kaasa, A., \& Vadi, M. (2010). How does culture contribute to innovation? Evidence from European countries (p. 586). Economics of Innovation and New Technology, 19(7), 583-604. 
Steele e Murray (2004) representam a importância das pessoas no desenvolvimento de uma cultura de inovação, conforme se indica na Figura 6.

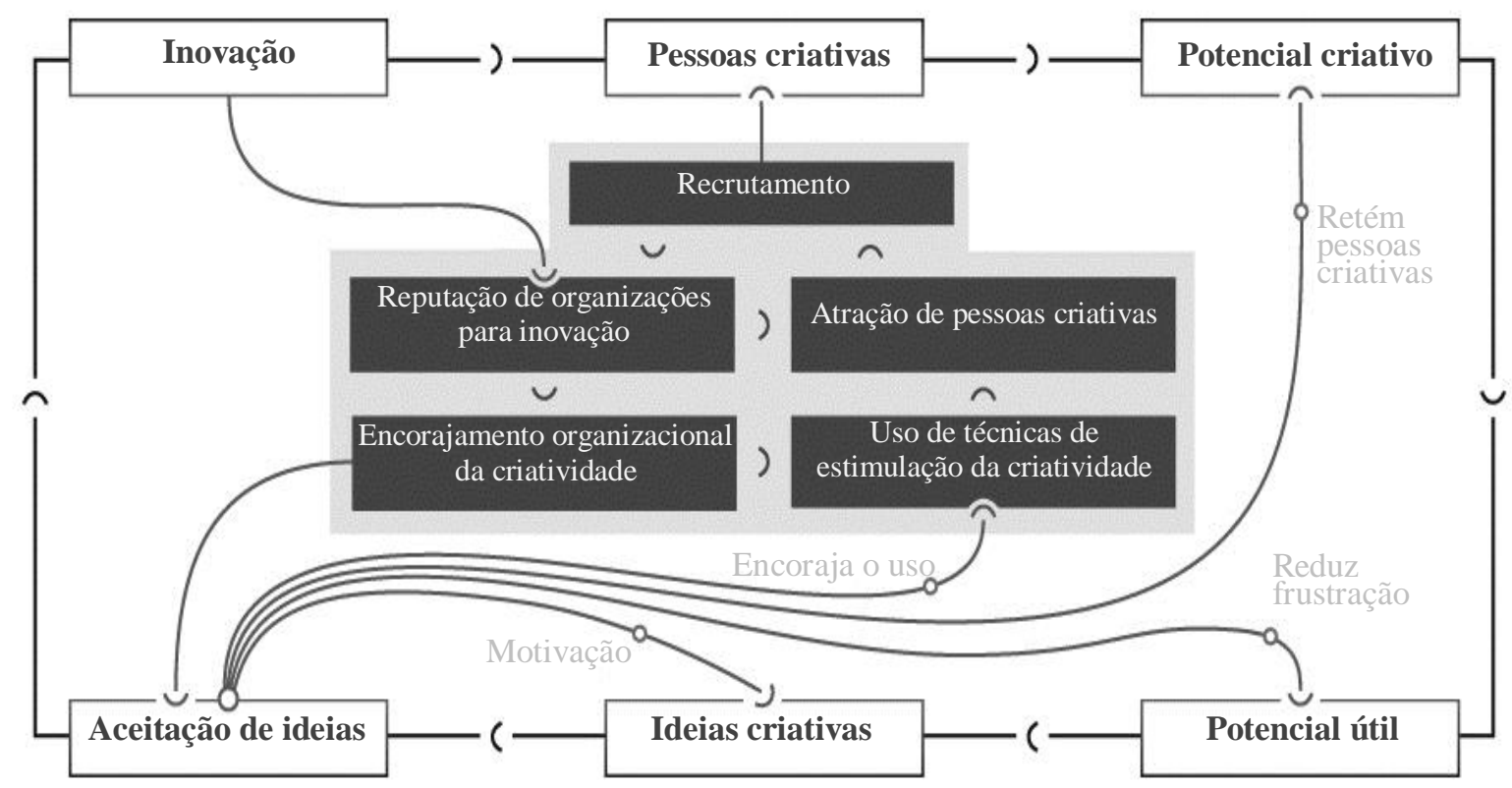

Figura 6. Perpetuação da Inovação Organizacional e Desenvolvimento.

Fonte: Adaptado de Steele, J., \& Murray, M. (2004). Creating, supporting and sustaining a culture of innovation (p. 321). Engineeering, Construction and Architectural Management, 11(5), 316-322. doi: 10.1108/09699980410558502

Steele e Murray (2004) destacam que as organizações devem atrair pessoas inovadoras e concluem que, embora a área de $P \& D$ seja vital para inovação, faz-se necessário que esta seja "complementada com uma estratégia para adaptação e difusão para aplicação em diferentes ambientes de negócios" (p. 322), para que se alcance vantagem competitiva no mercado e não se desmotivem os empregados.

A proposta de Ismail e Abdmajid (2007) integra aspectos apontados em outros modelos sobre cultura de inovação, objetivando uma visão mais integrada do construto. Cabe ressaltar que a maior parte dos modelos analisados por esses autores consta de teses de doutorado não publicadas e que os discutidos no presente estudo não foram por eles analisados. O modelo proposto por Ismail e Abdmajid (2007) é composto de cinco elementos, sendo variáveis independentes: liderança, estrutura, estratégia e cultura organizacional e variável dependente (resultado) a cultura de inovação, como pode ser observado na Figura 7. 


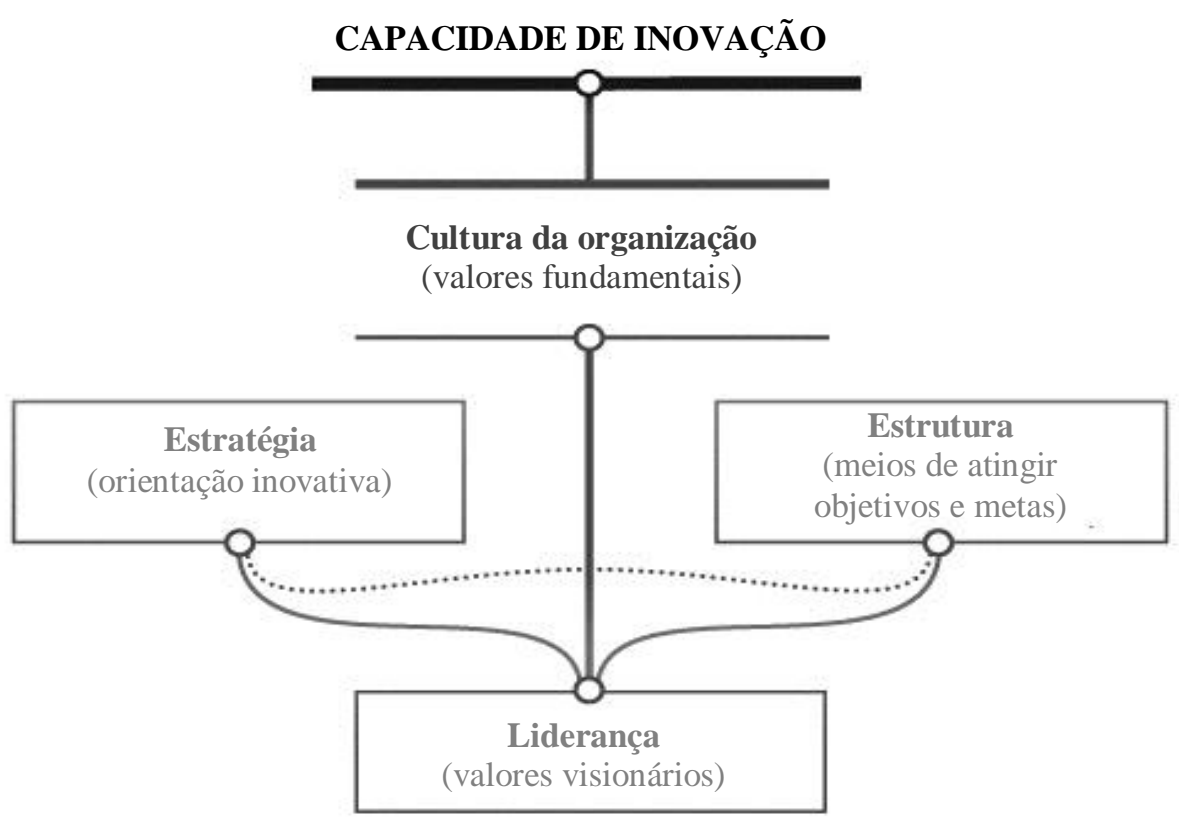

Figura 7. O Modelo Holístico de Cultura de Inovação.

Fonte: Adaptado de Ismail, W. K. W., \& Abdmajid, R. (2007). Framework of the culture of innovation: a revisit (p. 44). Journal Kemanusiaan, 9, 38-49.

Esses elementos, cuja descrição encontra-se na Tabela 4, atuam de forma integrada para a obtenção do resultado, que é uma cultura de inovação mais duradoura na qual se privilegiam aspectos associados ao fomento da inovação, tais como uma estrutura plana, autonomia e trabalho em equipes, comunicação, flexibilidade, tolerância ao risco, encorajamento e tomada de decisão compartilhada.

Tabela 4

Modelo de Cultura de Inovação

\section{ELEMENTOS DE INTERSEÇÃO CONTRIBUIÇÃO NO MODELO \\ QUE COMPÕEM O MODELO}

\begin{tabular}{ll}
\hline Liderança & $\begin{array}{l}\text { Papel central dos líderes principais na defesa de mudanças } \\
\text { organizacionais vitais para sustentar o potencial de inovação. }\end{array}$ \\
Estrutura & $\begin{array}{l}\text { Representa os métodos de atribuição de responsabilidades, o modo } \\
\text { como a organização interage e o modo como os membros se } \\
\text { comunicam. }\end{array}$ \\
Estratégia & $\begin{array}{l}\text { Representa as oportunidades que podem pavimentar o caminho para } \\
\text { criar e sustentar uma cultura de inovação. }\end{array}$ \\
Cultura organizacional & $\begin{array}{l}\text { Como fonte de recurso principal para nutrir a cultura, isto é, os } \\
\text { valores compartilhados, crenças e comportamentos. Funciona como } \\
\text { mediadora e é influenciada pelos líderes a fim de produzir uma } \\
\text { cultura de inovação. } \\
\text { É o resultado que determinará como criatividades são encorajadas, } \\
\text { como se corre riscos e a extensão de conhecimento compartilhado e } \\
\text { ideias é a norma. }\end{array}$ \\
\hline
\end{tabular}

Nota. Fonte: Construído a partir de Ismail, W. K. W., \& Abdmajid, R. (2007). Framework of the culture of innovation: a revisit (p. 45). Journal Kemanusiaan, 9, 38-49. 
A cultura organizacional é a "espinha dorsal da inovação organizacional que define e contém os valores básicos organizacionais. Ela é formada de acordo com valores de uma estrutura e estratégia que são inicialmente estabelecidas pelo líder da organização”, conforme Ismail e Abdmajid (2007, p. 45).

Brettel e Cleven (2011) adotam a visão baseada em recursos e apresentam um modelo de adoção de inovação em que a cultura de inovação é vista como uma faceta da cultura corporativa. Eles buscam analisar o impacto da abertura da firma ao conhecimento externo sobre a cultura de inovação, que é considerada como um fator latente refletido nas quatro seguintes dimensões: orientação para novas tecnologias, orientação para aprendizagem, disposição para correr riscos e orientação para o mercado futuro. Na Figura 8, pode-se identificar o modelo de pesquisa proposto por esses autores.

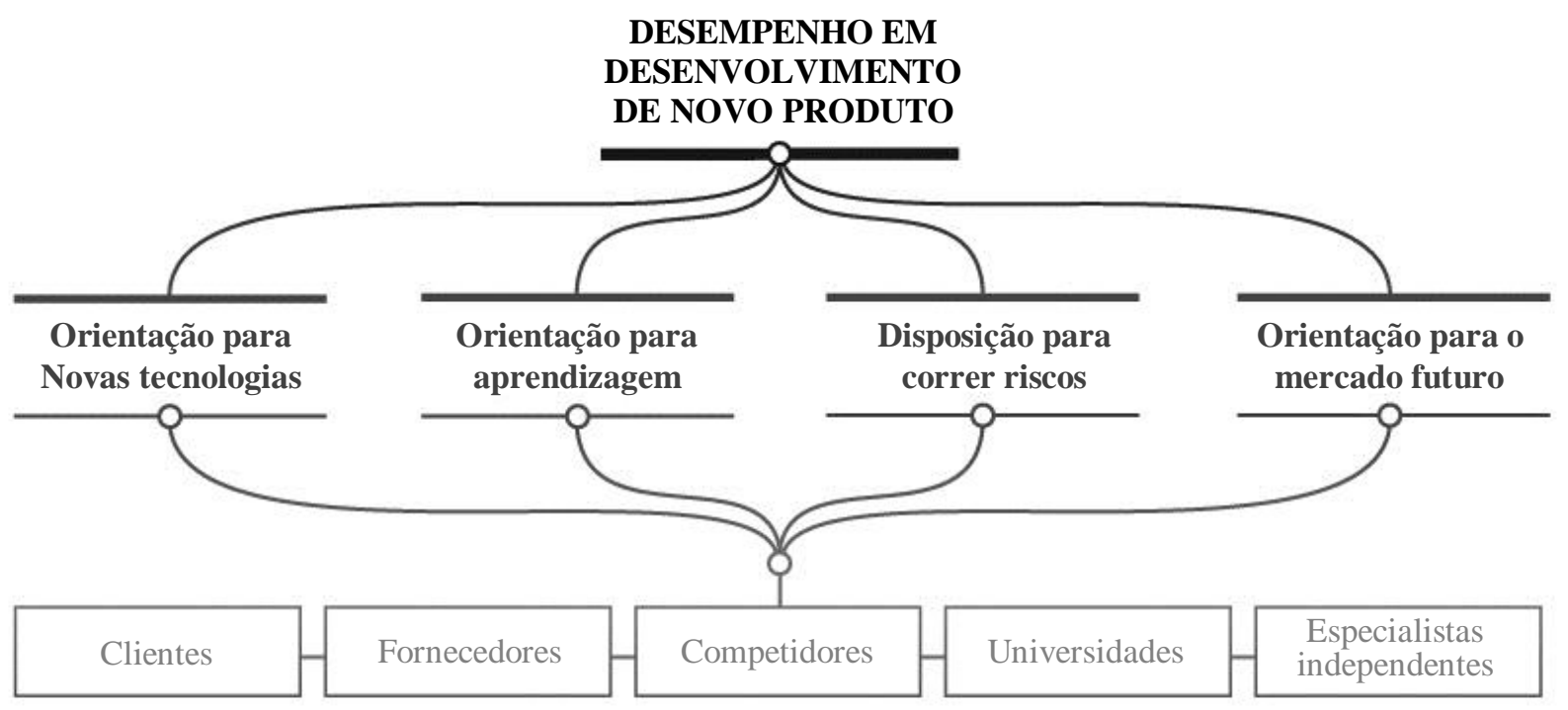

Figura 8. Modelo de Pesquisa e Hipóteses de Pesquisa.

Fonte: Adaptado de Brettel, M., \& Cleven, N. J. (2011). Innovation culture, collaboration with external partners and NPD performance (p. 255). Creativity and Innovation Management, 20(4), 253-272. doi: 10.1111/j.1467-8691.2011.00617.x

Os resultados do teste do modelo apresentado por Brettel e Cleven (2011), em relação a 254 empresas de base tecnológica, confirmaram as seguintes hipóteses: (a) inovação tecnológica teve uma relação positiva e significativa com atividades colaborativas com clientes, universidades e especialistas independentes; (b) orientação para aprendizagem e disposição para correr riscos tiveram uma associação positiva marginal com colaboração com clientes e especialistas independentes; (c) orientação para o mercado futuro teve uma relação positiva significativa com colaboração com fornecedores, universidades e especialistas independentes.

Em 2005, Jaskyte e Dressler realizaram um estudo com organizações de serviços sem fins lucrativos a fim de verificar se consenso cultural (o grau em que os valores organizacionais são compartilhados) e valores organizacionais são preditores de inovatividade organizacional. Trata-se de uma concepção antropológica cognitiva, segundo esses autores, em que cultura é definida como "valores organizacionais, normas, crenças e pressupostos que caracterizam organizações inovativas” (p. 26), partindo do pressuposto de que a homogeneidade dos valores organizacionais é essencial para uma organização tornar-se inovativa. A partir da revisão de literatura, relacionam um conjunto de valores, normas e pressupostos identificados como típicos de organizações inovadoras: desafiar o status quo; liberdade para fazer mudanças; trabalho em equipe; compartilhamento de metas comuns; relacionamento participativo e colegiado; compartilhamento de informações abertamente; flexibilidade e adaptabilidade; autonomia; correr riscos; orientação para resultados; criatividade; estimulação; desafio; orientação para o futuro; coesão; senso de família; comprometimento; aceitação de erros; dinamismo e empreendedorismo.

Com tal modelo, Jaskyte e Dressler (2005) propuseram-se a avaliar "o grau de diversidade e de compartilhamento entre indivíduos dentro da organização, assim como o conteúdo do que foi compartilhado" (p. 28) e a verificar a influência do tamanho da organização e das características da 
liderança. A cultura foi avaliada em sete dimensões: atenção ao detalhe; inovação, orientação para resultado, agressividade, orientação para equipe, estabilidade e orientação para pessoas. O teste do modelo revelou que inovatividade organizacional se relaciona significativamente e inversamente com consenso cultural e com a dimensão estabilidade que compõe a cultura organizacional. Consenso cultural, por sua vez, foi positivo e significativamente relacionado com orientação para equipe e estabilidade. Os autores salientam que "cultura altamente compartilhada pode não ser apropriada para promover inovação, especialmente considerando seu conteúdo" (p. 35). Acrescentam que "quanto mais alto for o consenso cultural em relação aos valores tais como estabilidade, segurança, baixo nível de conflito, previsibilidade, orientação para regras, orientação para equipe, trabalho em colaboração com outros, menos inovativa a organização pode ser" (Jaskyte \& Dressler, 2005, p. 35).

Laegreid, Roness e Verhoest (2011) adotaram uma perspectiva estrutural instrumental para analisar em que extensão 121 agências estatais norueguesas e flamengas desenvolvem cultura e atividade inovativa e propuseram o modelo conceitual constante da Figura 9.

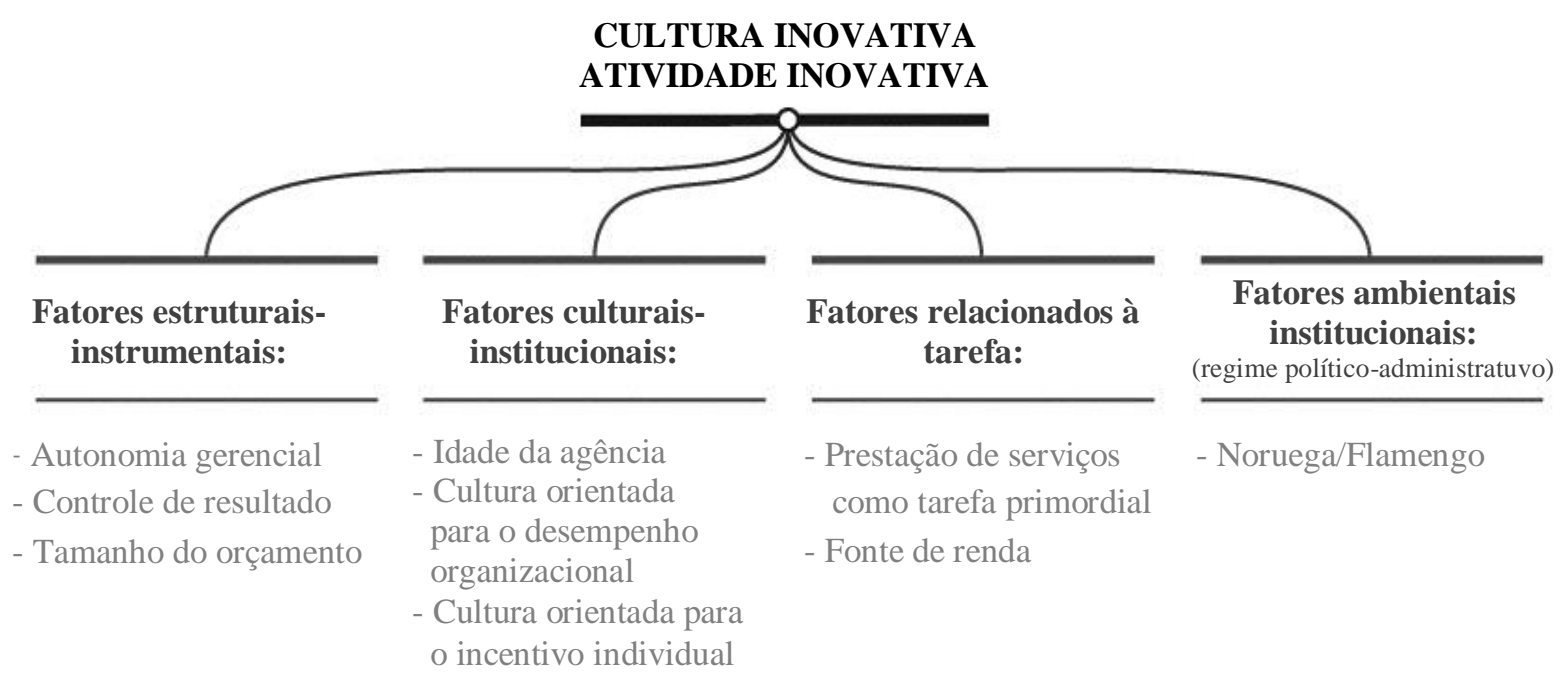

Figura 9. O Quadro Conceitual.

Fonte: adaptado de Laegreid, P., Roness, P. G., \& Verhoest, K. (2011). Explaining the innovative culture and activities of state agencies (p. 1325). Organization Studies, 32(10), 1321-1347. doi:10.1177/0170840611416744

Ao testar o modelo proposto na Figura 9, Laegreid et al. (2011) destacam que o fato de serem agências norueguesas e flamengas pode não diferenciar os resultados e que aspectos culturais e institucionais com foco em "valores de desempenho organizacional, assim como em valores de incentivo individual têm alguma importância, mas que as tarefas básicas e o tamanho do orçamento também importam em alguma medida" (p. 1339), reforçando a ideia de que a inovação não acontece em um vácuo.

Outros autores não estruturam um modelo teórico da relação entre cultura organizacional e inovação, porém destacam elementos que retratam a importância da cultura para que ocorra inovação, conforme pode ser visto na Tabela 5 , a seguir. 
Tabela 5

\section{Outras Evidências da Relação entre Cultura Organizacional e Inovação}

\begin{tabular}{ll}
\hline AUTORES & RESULTADOS VERSUS INOVAÇÃO \\
\hline Susanj (2000) & Utiliza uma única medida de clima e cultura de inovação que deriva de um \\
& modelo de funcionamento organizacional com duas dimensões (controle versus \\
& flexibilidade e foco interno versus externo). As duas dimensões combinadas \\
& produzem quatro orientações, a saber: suporte (orientação para flexibilidade e \\
& foco interno); inovação (orientação para flexibilidade e foco externo); objetivos \\
& (orientação para controle e foco externo) e regras (orientação para controle e \\
& foco interno).
\end{tabular}

Westwood e Low (2003)

Culturas são inovativas em seus próprios sistemas na extensão em que as circunstâncias exigem soluções criativas e inovadoras.

Mavondo e Farrell (2003)

Cultura organizacional, considerada um ativo estratégico relacionado à estratégia organizacional e orientação de mercado, relaciona-se de forma positiva e significativa com inovação.

De Silva e Takeda (2005)

Os pressupostos, normas e valores podem atuar como barreiras à inovação sendo necessária uma mudança atitudinal e comportamental, especialmente com a crença nas competências humanas e num ambiente em que haja flexibilidade e seja empreendedor.

Zairi e Al-Mashari (2005) No desenvolvimento de uma cultura sustentável de inovação exige educação e treinamento, rede de inovação e recompensa e reconhecimento pela inovação.

Shieh e Wang (2010)

O processo de realização e inovação da informação, assim como a integração efetiva de recursos e inovação de informação, pode ser aprimorado por uma cultura que ofereça oportunidades de os empregados aprenderem uns com os outros como se fosse um ambiente familiar acolhedor.

Tuan e Venkatesh (2010)

A visão de causa, composto de estrutura organizacional, mecanismos de suporte e estimuladores de inovação influenciam adoção de inovação tecnológica.

Hernández-Mogollon, Cepeda- A extensão em que a empresa alcança um contexto de mente aberta ("a Carrión, Cegarra-Navarro e disposição para considerar ideias e opiniões que são novas ou diferentes”) irá Leal-Millán (2010) determinar a extensão na qual a inovação se realiza.

Valencia, Valle e Jiménez Cultura organizacional pode aumentar inovação de produto, mas também pode (2010) "inibi-la dependendo dos valores que a cultura fomenta" (p. 474). Identificaram correlações significativas positivas entre cultura adhocráticas (enfatizam flexibilidade, mudança, criatividade, empreendedorismo e correr riscos e é externamente orientada) e inovação; e negativa entre culturas hierárquicas (orientadas pelo controle e foco interno) e inovação.

Lin e McDonough (2011)

O líder ocupa um papel estratégico na construção de uma cultura de inovação e deve enfrentar as forças contraditórias que coexistem nas organizações, da inércia e manutenção do status quo e da inovação e mudança.

Moraes, Souza, Costa e Confirmaram as hipóteses de que a cultura organizacional se relaciona de Cosentino (2011) forma positiva com cooperação e esta, por sua vez, relaciona-se positivamente com inovação. Concluem que a estrutura de uma organização e sua cultura "criam o ambiente para interação e cooperação que promovem o desenvolvimento de inovações”. (p. 125)

Entre os aspectos que favorecem a construção de uma cultura de inovação ou variáveis da cultura organizacional associadas à inovação, destacam-se: a atuação da liderança (Bravo-Ibarra \& Herrera, 2009; Çakar \& Ertürk, 2010; Godoy \& Peçanha, 2009; Janiunaite \& Petraite, 2010; Jaskyte \& Dressler, 2005; Le Bas \& Lauzikas, 2010; Lin \& McDonough, 2011; E. Martins \& Martins, 2002; Mclean, 2005; Twati \& Gammack, 2006; Zairi \& Al-Mashari, 2005; Zien \& Buckler, 1997); comunicação e 
compartilhamento de informações (Das, 2003; Dombrowski et al., 2007; E. C. Martins \& Terblanche, 2003; Godoy \& Peçanha, 2009; Ismail \&; Abdmajid, 2007; Janiunaite \& Petraite, 2010; Johannessen \& Olsen, 2011); correr riscos (Apekey et al., 2011; Brettel \& Cleven, 2011; Das, 2003; Ismail \& Abdmajid, 2007; Serra et al., 2007; Valencia, Valle, \& Jiménez, 2010). A intenção de inovar e ser bem-sucedido ou estratégia de inovação também foi um aspecto citado por alguns autores, tais como Zien e Buckler (1997); E. Martins e Martins (2002) Das (2003); Dobni (2008); Godoy e Peçanha (2009), entre outros. Mas não basta ter a intenção de se obter uma cultura propícia à inovação, deve-se traçar um conjunto de estratégias que facilite o compartilhamento de valores e pressupostos a ela associados.

Estudos mais recentes evidenciam os dois focos encontrados no levantamento apresentado neste estudo: a proposição de um novo construto denominado cultura de inovação e pesquisas que buscam analisar a relação entre cultura organizacional e inovação. Naranjo-Valencia, Jiménez e Sanz-Valle (2012), por exemplo, objetivaram analisar se a cultura organizacional seria um determinante da inovação na empresa. Adotaram como medidas de inovação (de produto, de processo e de gestão ou administrativa) informações sobre número de inovações introduzidas na empresa, o esforço feito para inovar, gastos, pessoas, tempo, entre outros, e adotaram duas escalas para avaliar cultura organizacional, construídas e validadas por outros autores. Entre os resultados, destaca-se que a cultura adhocrática, a que possui "orientação externa" e "valoriza mais a flexibilidade do que a estabilidade", "típica de empresas que buscam ser líderes no mercado e que operam em uma situação de mudança permanente" (Naranjo-Valencia, Jiménez, \& Sanz-Valle, 2012, p. 65), apresentou relações positivas e significativas com todos os tipos de inovação. Por sua vez, a cultura hierárquica, com orientação interna, que "busca a estabilidade e o controle" e tem como valores principais "a eficiência, o cumprimento de normas e a formalização de processos, assim como a estabilidade no emprego (p. 66), revelou relações negativas e significativas com os tipos de inovação. Machado, Carvalho e Heinzmann (2012) também buscaram identificar como a cultura organizacional interfere na inovação. Para tanto, empregaram medidas desenvolvidas e validadas por outros autores, sendo que adaptaram uma medida de processo de inovação denominando-a de avaliação do ambiente de inovação. Perceberam, então, melhorias na percepção do ambiente de inovação ao introduzirem a variável cultura organizacional. São sugeridos estudos em novos ambientes para que se verifique o impacto da cultura organizacional na inovação, tendência essa verificada nos estudos mais recentes.

Em relação ao foco principal deste artigo, Wolf, Kaudela-Baum e Meissner (2011) realizaram estudo longitudinal, durante três anos, com um desenho cuidadoso e detalhado da pesquisa, com o propósito de contribuir para a compreensão da cultura de inovação em pequenas e médias empresas. Embora tenham encontrado variações entre as 85 empresas estudadas, destacam a importância do papel da liderança, que deve atuar de forma diferenciada de acordo com as características das empresas; a disponibilidade de recursos financeiros; "integração e cooperação em redes e apoio das autoridades públicas" (p. 266). Harbi, Anderson e Amamou (2014), por sua vez, realizaram quatro estudos de casos exploratórios em empresas da Tunísia a fim de avaliar se, na "ausência de condições inovativas fundamentais" (p. 132), pequenas empresas de tecnologia da informação podem ter uma cultura de inovação considerada como provendo "um modo de pensar e um modo de agir que auxilia a inovação" (p. 136) e apontaram a socialização do conhecimento como uma característica central da cultura de inovação, bem como a importância da interação das empresas que devem facilitar conexões criando oportunidades de interação das pessoas.

Também se identificou um estudo realizado, por Uzkurt, Kumar e Ensari (2013), sobre um construto similar à cultura de inovação, denominado de prontidão para inovação. As características mais importantes da propensão para inovar referem-se à cultura, à estrutura e ao clima organizacional, sendo a cultura organizacional e as atitudes dos gestores os aspectos centrais para a inovação. 


\section{Considerações Finais}

Pôde-se evidenciar, a partir da análise dos conceitos e modelos teóricos presentes na bibliografia revisada, que a cultura de inovação é considerada como algo almejado nas organizações para a melhoria de seu desempenho e de sua vantagem competitiva. Nesse sentido, as pesquisas, de algum modo, corroboram tal associação. Este artigo apontou a complexidade de fatores que envolvem a cultura de inovação ou aspectos de uma cultura organizacional relacionada à inovação, pontos comuns, divergências, desafios e lacunas para pesquisas futuras, mostrando o quão desafiante é a busca de consenso sobre o tema.

Se a cultura de inovação é parte da cultura maior de uma organização, para que ela se desenvolva, faz-se necessário lidar com aspectos restritivos à cultura nesse contexto, tais como o controle (Mclean, 2005); distância do poder e evitar incertezas (Çakar \& Ertürk, 2010; Kaasa \& Vadi, 2010).

Predominam pesquisas quantitativas sobre cultura de inovação cuja produção científica ainda é recente, revelando a necessidade de se aprofundar mais a análise das diferentes proposições dos autores a partir de estudos qualitativos, especialmente por estudos de casos, que, de acordo com Hartley (2004), são indicados para "explorar processos ou comportamentos novos ou emergentes" (p. 325). Gondim et al. (2005) assinalam que no estudo de caso instrumental "se espera obter insights que dêem suporte à generalização teórica no futuro" (p. 53). Eisenhardt (1989), por sua vez, ressalta que, quando se tem o propósito de construir teorias, os estudos de casos "combinam métodos de coleta de dados, tais como arquivos, entrevistas, questionários e observações" (p. 534), que podem se constituir em uma sugestão de estudos futuros sobre cultura de inovação. Entretanto pôde-se perceber, em três estudos mais recentes, que surgem pesquisas qualitativas com estudos de casos (Harbi, Anderson, \& Amamou, 2014); grupos focais (Uzkurt, Kumar, \& Ensari, 2013) e desenhos mais complexos de pesquisa, com estudos longitudinais como realizaram Wolf et al. $(2011)^{(1)}$.

Em concordância com o que salientam Janiunaite e Petraite (2010), o termo cultura de inovação é amplamente empregado, mas carece de definições apropriadas talvez, como observam Ismail e Abdmajid (2007), pelo fato de que "compreender e criar uma cultura de inovação está entre os mais difíceis desafios enfrentados por pesquisadores e gestores" (p. 45). Ahmed (1998) reforça tal ideia ao afirmar que "virtualmente todas as empresas falam sobre inovação e a importância de 'fazer' inovação, muitas realmente tentam fazê-la, e somente poucas realmente têm sucesso em fazê-la" (p. 30). Aduz, ainda, que o conceito de cultura por si só já é complexo, pois a cultura corporativa deriva de "tentativas antropológicas de compreender sociedades inteiras" (Ahmed, 1998, p. 32) e, com o passar do tempo, passou a ser utilizada para designar nações, corporações, departamentos e até equipes de negócios.

Em relação aos modelos teóricos, E. C. Martins e Terblanche (2003) salientam que modelos baseados em abordagem de sistemas abertos são os mais adequados, pois oferecem "uma abordagem holística que permite a investigação da interdependência, interação e inter-relação de diferentes subsistemas e elementos da cultura organizacional em uma organização" (p. 73). Tais modelos consideram "padrões de interação entre pessoas, papéis, tecnologia e ambiente externo" (p. 73) que denotam um ambiente muito complexo. Uma abordagem holística para inovação também é enfatizada por Ahmed (1998), assim como o fato de a cultura poder atuar como facilitadora ou inibidora da inovação. Esse autor usa uma metáfora para expressar a cultura inovadora de um sentimento que faz parte da "psique prevalecente em cada organização" (p. 31).

Embora a literatura seja ampla e aponte "uma ligação muito forte entre inovatividade e cultura" (Dobni, 2008, p. 542), muito há de se explorar para saber como ocorre tal relação e como contribuir para a construção de uma cultura de inovação no contexto organizacional. Mesmo com as limitações do levantamento bibliográfico, especialmente de obras que possam não ter sido incluídas, destaca-se que vários aspectos identificados podem contribuir para a geração de novos estudos pertinentes ao tema a partir de maior aprofundamento teórico. Em especial, a análise dos modelos propostos pelos diferentes autores e a necessidade de delimitar o conceito de cultura de inovação, que é um construto teórico em pleno processo de desenvolvimento. 


\section{Nota}

${ }^{1}$ Documento disponível na base SAGE, a partir de 2014.

\section{Referências}

Ahmed, P. K. (1998). Culture and climate for innovation. European Journal of Innovation Management, l(1), 30-43. doi: 10.1108/14601069810199131

Amabile, T. (1996). Creativity and innovation in organizations. Harvard Business School, 5, 1-15.

Apekey, T. A., McSorley, G., Tilling, M., \& Siriwardena, A. N. (2011). Room for improvement? Leadership, innovation culture and uptake of quality improvement methods in general practice. Journal of Evaluation in Clinical Practice, 17(2), 311-318. doi: 10.1111/j.13652753.2010.01447.x

Bravo-Ibarra, E. R., \& Herrera, L. (2009). Capacidad de innovación y configuración de recursos organizativos. Intagible Capital, 5(3), 301-320. doi: 10.3926/ic.2009

Brettel, M., \& Cleven, N. J. (2011). Innovation culture, collaboration with external partners and NPD performance. Creativity and Innovation Management, 20(4), 253-272. doi: 10.1111/j.14678691.2011.00617.x

Çakar, N. D., \& Ertürk, A. (2010). Comparing innovation capability of small and medium-sized enterprises: examining the effects of organizational culture and empowerment. Journal of Small Business Management, 48(3), 325-359. doi: 10.1111/j.1540-627X.2010.00297.x

Das, G. S. (2003). Preparedness for innovation: an Indian perspective. Global Business Review, 4(1), 27-39.

De Silva, S., \& Takeda, J. (2005). Influence of culture on innovation barriers: the case of Sri Lankan food processing industry. Journal of Applied Sciences, 5(7), 308-1315. doi: 10.3923/jas.2005.1308.1315

Dobni, C. B. (2008). Measuring innovation culture in organizations: the development of a generalized innovation culture construct using exploratory factor analysis. European Journal of Innovation Management, 11(4), 539-559. doi: 10.1108/14601060810911156

Dombrowski, C., Kim, J. Y., Desouza, K. C., Brabanza, A., Papagari, S., Baloh, P., \& Jha, S. (2007). Elements of innovative cultures. Knowledge and Process Management, 14(3), 190-202. doi: $10.1002 / \mathrm{kpm} .279$

Duygulu, E., Kök, R., \& Özdemir, A. (2008, November). Factors influencing innovation in SMEs in Turkey: an interregional comparison. Proceedings of the Institute for Small Business \& Entrepreneurship Conference, Belfast, N. Ireland, 31.

Eisenhardt, K. M. (1989). Building theories from case study research. Academy of Management Review, 14(4), 532-550. doi: 10.5465/AMR.1989.4308385

Godoy, R. S. P., \& Peçanha, D. L. N. (2009). Cultura organizacional e processos de inovação: um estudo psicossociológico em empresa de base tecnológica. Boletim Academia Paulista de Psicologia, 29(1), 142-163. 
Gondim, S. M. G., Sá, M. O., Melo, L. C. T., Barbosa, S. T., Vasconcellos, C. M., \& Gomes, S. T. (2005). Da descrição do caso à construção da teoria ou da teoria à exemplificação do caso? Uma das encruzilhadas da produção de conhecimento em administração e áreas afins. $O \& S, 12(35)$, 47-68.

Harbi, S. E., Anderson, A. R., \& Amamou, M. (2014). Innovation culture in small Tunisian ICT firms. Journal of Small Business and Enterprise Development, 21(1), 132-151. doi: 10.1108/JSBED06-2013-0086

Hartley, J. (2004). Case study research. In C. Cassell \& G. Symon (Eds.), Essential guide to qualitative methods in organizational research (pp. 323-333). London: Sage.

Hernández-Mogollon, R., Cepeda-Carrión, G., Cegarra-Navarro, J. G., \& Leal-Millán, A. (2010). The role of cultural barriers in the relationship between open-mindedness and organizational innovation. Journal of Organizational Change Management, 23(4), 360-376. doi: $10.1108 / 09534811011055377$

Ismail, W. K. W., \& Abdmajid, R. (2007). Framework of the culture of innovation: a revisit. Journal Kemanusiaan, 9, 38-49.

Janiunaite, B., \& Petraite, M. (2010). The relationship between organizational innovative culture and knowledge sharing in organization: the case of technological innovation implementation in a telecommunication organization. Socialiniai Mokslai, 3(69), 14-23.

Jaskyte, K., \& Dressler, W. W. (2004). Studying culture as an integral aggregate variable: organizational culture and innovation in a group of nonprofit organizations. Field Methods, 16(3), 265-284. Recuperado de http://fmx.sagepub.com/content/16/3/265. doi: 10.1177/1525822X03262281

Jaskyte, K., \& Dressler, W. W. (2005). Organizational culture and innovation in nonprofit human service organizations. Administration in Social Work, 29(2), 23-41. doi: 10.1300/J147v29n02_03

Johannessen, J.-A., \& Olsen, B. (2011). Projects as communicating systems: creating a culture of innovation and performance. International Journal of Information Management, 31(1), 30-37. doi: 10.1016/j.ijinfomgt.2010.04.006

Kaasa, A., \& Vadi, M. (2010). How does culture contribute to innovation? Evidence from European countries. Economics of Innovation and New Technology, 19(7), 583-604.

Laegreid, P., Roness, P. G., \& Verhoest, K. (2011). Explaining the innovative culture and activities of state agencies. Organization Studies, 32(10), 1321-1347. doi: 10.1177/0170840611416744

Le Bas, C., \& Lauzikas, M. (2010). Determinants of innovation culture and major impacts on the innovation strategy: the case of the information technology sector in Lithuania. Social Sciences Studies, 4(8), 125-139.

Lin, H., \& McDonough, E. F., III (2011). Investigating the role of leadership and organizational culture in fostering innovation ambidexterity. IEEE Transactions on Engineering Management, 58(3), 497-509. doi: 10.1109/TEM.2010.2092781

Machado, D. D. P. N., Carvalho, L. C., \& Heinzmann, L. M. (2012). Ambiente favorável ao desenvolvimento de inovações e cultura organizacional: integração de duas perspectivas de análise. Revista de Administração, 47(4), 715-729. doi: 10.5700/rausp1069

Machado, D. D. P. N., \& Vasconcellos, M. A. (2007). Organizações inovadoras: existe uma cultura específica que faz parte deste ambiente? Revista de Gestão USP, 14(4), 15-31.

Mambrini, A. B., Dattein, E., Medina, J. A. A., Cintho, S., \& Maccari, E. A. (2011). Cultura inovadora na pequena e média empresa. Revista de Gestão e Projetos, 2(1), 26-51. doi: 10.5585/gep.v2i1.34 
Martins, E., \& Martins, N. (2002). An organizational culture model to promote creativity and innovation. Journal of Industrial Psychology, 28(4), 58-65.

Martins, E. C., \& Terblanche, F. (2003). Building organizational culture that stimulates creativity and innovation. European Journal of Innovation Management, 6(1), 64-74. doi: $10.1108 / 14601060310456337$

Mavondo, F., \& Farrell, M. (2003). Cultural orientation: its relationship with market orientation, innovation and organizational performance. Management Decision, 41(3), 241-249. doi: $10.1108 / 00251740310468054$

Mclean, L. D. (2005). Organizational culture's influence on creativity and innovation: a review of the literature and implications for human resource development. Advances in Developing Human Resources, 7(2), 226-246. doi: 10.1177/1523422305274528

Moraes, C. A.de, Souza, S. S. de, Costa, A. C. F. da, \& Cosentino, H. M. (2011). Configuração e cultura organizacional, cooperação e inovação: análise de um modelo de equações estruturais em empresas fabricantes de equipamentos médicos. Revista Eletrônica de Ciência Administrativa, 10(1), 111-127. Recuperado de http://revistas.facecla.com.br/index.php/recadm/article/download/632/532. doi: 10.5329/RECADM.20111001008

Naranjo-Valencia, J. C., Jiménez, D. J., \& Sanz-Valle, R. (2012). Es la cultura organizativa un determinante de la innovación de la empresa? Cuadernos de Economía y Dirección de la Empresa, 15(2), 63-72. doi: 10.1016/j.cede.2011.07.004

Serra, F. A. R., Fiates, G. G., \& Alperstedt, G. D. (2007). Inovação na pequena empresa: um estudo de caso na Tropical Brasil. Journal of Technology Management \& Innovation, 2(2), 170-183.

Shieh, C., \& Wang, I. (2010). A study of the relationships between corporate core competence, management innovation and corporate culture. The International Journal of Organizational Innovation, 2(3), 395-411.

Steele, J., \& Murray, M. (2004). Creating, supporting and sustaining a culture of innovation. Engineeering, Construction and Architectural Management, 11(5), 316-322. doi: $10.1108 / 09699980410558502$

Susanj, Z. (2000). Innovative climate and culture in manufacturing organizations: differences between some European countries. Social Science Information, 39(2), 349-361. doi: $10.1177 / 053901800039002011$

Tuan, L. T., \& Venkatesh, S. (2010). Organizational culture and technological innovation adoption in private hospitals. International Business Research, 3(3), 144-153. doi: 10.5539/ibr.v3n3p144

Twati, J. M., \& Gammack, J. G. (2006). The impact of organizational culture innovation on the adoption of IS/IT: the case of Libya. Journal of Enterprise Information Management, 19(1-2), 175-191. doi: $10.1108 / 17410390610645076$

Uzkurt, C., Kumar, R., \& Ensari, N. (2013). Assessing organizational readiness for innovation: an exploratory study on organizational characteristics of innovativeness. International Journal of Innovation and Technology Management, 10(4). doi: 10.1142/S0219877013500181

Valencia, J. C. N., Valle, R. S., \& Jiménez, D. J. (2010). Organizational culture as determinant of product innovation. European Journal of Innovation Management, 13(4), 466-480. doi: $10.1108 / 14601061011086294$ 
Van De Ven, A. H., \& Angle, H. L. (2000). An introduction to the Minnesota innovation research program. In A. H. Van De Ven, H. L. Angle, \& M. S. Poole (Eds.), Research on the management of innovation: the Minnesota studies (pp. 3-30). New York: Oxford University Press.

Van Reine, P. P., \& Dankbaar, B. (2011). The dynamic interaction between corporate and regional cultures: the case of southeast Netherlands. Tijdschrift voor economische en sociale geografie, 102(5), 532-547. doi: 10.1111/j.1467-9663.2011.00657.x

West, M. A., \& Anderson, N. R. (1996). Innovation in top management teams. Journal of Applied Psychology, 81(6), 680-693. doi: 10.1037/0021-9010.81.6.680

Westwood, R., \& Low, D. R. (2003). The multicultural muse: culture, creativity and innovation. International Journal of Cross Cultural Management, 3(2), 235-259. doi: $10.1177 / 14705958030032006$

Wolf, P., Kaudela-Baum, S., \& Meissner, J. O. (2011). Exploring innovating cultures in small and medium-sized enterprises: findings from Central Switzerland. International Small Business Journal, 30(3), 242-274. doi: 10.1177/0266242610386666

Zairi, M., \& Al-Mashari, M. (2005). Developing a sustainable culture of innovation management: a perspective approach. Knowledge and Process Management, 12(3), 190-202. doi: $10.1002 / \mathrm{kpm} .229$

Zien, K. A., \& Buckler, S. A. (1997). From experience dreams to market: crafting a culture of innovation. Journal of Production Innovation Management, 14(4), 274-287. doi: 10.1016/S07376782(97)00029-5 